\title{
Hubungan antara Perempuan Usia Reproduksi dengan Kejadian Leiomioma Uteri dan Adenomiosis Uteri di Rumah Sakit Umum Daerah Cengkareng Jakarta Barat Tahun 2017-2019
}

\author{
Reyhan Alfarizan $^{1}$, Mieke Marindawati ${ }^{2 *}$ \\ 1) Pendidikan Dokter Umum, Fakultas Kedokteran, Universitas Muhammadiyah Jakarta \\ 2) Departemen Patologi Anatomi, Fakultas Kedokteran dan Kesehatan, Universitas Muhammadiyah Jakarta \\ *miekemarind@yahoo.com
}

\begin{abstract}
Background: Abnormal uterine bleeding (AUB) affects 10\%-30\% of women in reproductive age and 50\% of women in perimenopause. The most common causes of PUA are uterine leiomyoma and uterine adenomyosis. The prevalence of uterine leiomyoma together with uterine adenomyosis has been reported in the literature is 15\%-57\%. Purposes: to examine the correlation between reproductive age women to the occurrence of uterine leiomyoma and adenomyosis in Cengkareng Regional General Hospital, West Jakarta, 2017-2019. Methods: this study uses a descriptive-analytic with a retrospective cross sectional using medical record. This research was conducted at Cengkareng Regional General Hospital, West Jakarta, in November-December 2019. Data analysis was performed univariate and bivariate with ChiSquare test in SPSS Ver.25. Results: from the 153 samples, the diagnosis of uterine leiomyoma 77 cases (50.4\%), 76 cases (49.7\%) reproductive age and 1 case $(0.7 \%)$ non-reproductive age. For the diagnosis of adenomyosis 37 cases (24.1\%), 27 cases (17.6\%) reproductive age and 10 cases (6.5\%) non-reproductive age. And for the diagnosis of uterine leiomyoma and adenomyosis 39 cases (25.5\%), 28 cases (18.3\%) reproductive age and 11 cases (7.2\%) nonreproductive age. Age variables related to the incidence of leiomyoma and adenomyosis $p$ value=0,000. Conclusion: There is a correlation between reproductive age women to the occurrence of uterine leiomyoma and adenomyosis.
\end{abstract}

Keywords: Reproductive age women, uterine leiomyoma, uterine adenomyosis.

\begin{abstract}
ABSTRAK
Latar Belakang: Pendarahan uterus abnormal (PUA) mempengaruhi 10\% - 30\% wanita usia reproduksi dan 50\% wanita perimenopause. Penyebab tersering PUA adalah leiomioma uteri dan adenomiosis uteri. Prevalensi adenomiosis uteri bersamaan dengan leiomioma uteri telah dilaporkan dalam literatur adalah 15\%-57\%. Tujuan: untuk mengetahui hubungan antara perempuan usia reproduksi dengan kejadian leiomioma uteri dan adenomiosis uteri di Rumah Sakit Umum Daerah Cengkareng Jakarta Barat tahun 2017-2019. Metode: jenis penelitian ini merupakan deskriptif analitik dengan pendekatan retrospective cross sectional menggunakan rekam medis. Penelitian ini dilakukan di Rumah Sakit Umum Daerah Cengkareng Jakarta Barat pada bulan November-Desember 2019. Analisis data dilakukan secara univariat dan bivariat dengan uji Chi-Square menggunakan SPSS Ver.25. Hasil: dari 153 rekam medis, didapatkan leiomioma uteri 77 kasus $(50,4 \%)$, yaitu usia reproduksi 76 kasus $(49,7 \%)$ dan usia tidak reproduksi 1 kasus $(0,7 \%)$. Untuk diagnosis adenomiosis uteri 37 kasus $(24,1 \%)$, yaitu usia reproduksi 27 kasus $(17,6 \%)$ dan usia tidak reproduksi 10 kasus (6,5\%). Dan untuk diagnosis
\end{abstract}


leiomioma uteri dan adenomiosis uteri 39 kasus (25,5\%), usia reproduksi 28 kasus (18,3\%) dan usia tidak reproduksi 11 kasus $(7,2 \%)$. Variabel usia berhubungan dengan kejadian leiomioma dan adenomiosis p-value $=0,000$. Kesimpulan: ada hubungan antara perempuan usia reproduksi dengan kejadian leiomioma dan adenomiosis uteri.

Kata kunci: Perempuan usia reproduksi, leiomioma uteri, adenomiosis uteri.

\section{PENDAHULUAN}

Perempuan usia reproduksi atau wanita usia subur (WUS) merupakan wanita yang berusia 15-49 tahun baik yang berstatus kawin, janda maupun yang belum menikah (1).

Pendarahan uterus abnormal (PUA) mempengaruhi $10 \%$ sampai $30 \%$ wanita usia reproduksi dan $50 \%$ wanita perimenopause (2). Leiomioma uteri dan adenomiosis uteri merupakan dua penyebab paling sering menyebabkan PUA (3). Bahkan leiomioma uteri dan adenomiosis uteri secara spesifik dimasukan dalam klasifikasi PALM-COEIN FIGO (Polyp, Adenomyosis, Leiomyoma, Malignancy dan Hyperplasia, Coagulopathy, Ovulatory Disfunction, Endometrial, Iatrogenic, and not yet classified - International Federation of Gynecology and Obstetric) (4).

Leiomioma uteri adalah merupakan tumor jinak yang struktur utamanya adalah otot polos rahim. Leiomioma uteri terjadi pada $20 \%$ - 25\% di usia reproduksi. Insidennnya 3 - 9 kali lebih banyak pada ras kulit berwarna dibandingkan dengan ras kulit putih (5). Diperkirakan insiden leiomioma uteri sekitar 20\%-30\% dari seluruh wanita. Di Indonesia leiomioma uteri ditemukan 2,39\% - 11,7\% pada semua penderita ginekologi yang dirawat (6).

Adenomiosis uteri ditandai oleh pembesaran rahim yang disebabkan oleh endometrium ektopik baik kelenjar dan stroma yang terletak di dalam miometrium. Diagnosis biasanya didasarkan pada temuan histopatologis pada spesimen bedah. Oleh karena itu, insiden yang dilaporkan dalam spesimen histerektomi bervariasi tergantung pada kriteria histologis, tetapi berkisar antara $20 \%$ hingga $60 \%$ (2). Dalam spesimen histerektomi, kejadian adenomiosis uteri yang dilaporkan dalam literatur bervariasi, mulai dari yang tinggi $61,5 \%$ hingga yang rendah dari $8,8 \%(7)$.

Leiomioma uteri dan adenomiosis uteri sering muncul bersama (8). Prevalensi adenomiosis uteri bersamaan dengan leiomioma uteri telah dilaporkan dalam literatur berkisar antara $15-57 \%$, menurut evaluasi spesimen uterus wanita dengan leiomioma uteri $(9,10)$. Leiomioma uteri ditemukan pada masa reproduksi dan adenomiosis uteri ditemukan pada akhir masa reproduksi $(2,11)$.

Tujuan dari penelitian ini adalah untuk mengetahui adakah hubungan antara perempuan usia reproduksi dengan kejadian leiomioma uteri dan adenomiosis uteri di Rumah Sakit Umum Daerah Cengkareng Jakarta Barat tahun 20172019.

\section{METODE}

Jenis penelitian ini merupakan deskriptif analitik dengan pendekatan retrospective cross sectional atau studi potong lintang retrospektif dengan menggunakan data rekam medis. Penelitian ini dilakukan di Rumah Sakit Umum Daerah Cengkareng Jakarta Barat pada Bulan November Desember 2019. Populasi dalam penulisan 
ini adalah seluruh rekam medis dari pasien dengan diagnosa leiomioma uteri, adenomiosis uteri atau keduanya di Rumah Sakit Umum Daerah Cengkareng Jakarta Barat periode tahun 2017-2019. Sampel pada penelitian ini berjumlah 153 sampel rekam medis. Populasinya adalah seluruh rekam medis dari pasien dengan diagnosa leiomioma uteri, adenomiosis uteri atau keduanya dengan variabel yang diteliti pada penelitian ini adalah perempuan usia reproduksi sebagai variabel independen dan kejadian leiomioma uteri dan adenomiosis uteri sebagai variabel dependen. Tehnik pengambilan sampel pada penelitian ini adalah tehnik total sampling.

Analisis data dilakukan secara univariat untuk mendapatkan gambaran distribusi frekuensi masing-masing variabel dan bivariat untuk mengetahui hubungan antara dua variabel menggunakan uji chi-square pada aplikasi pengolahan data Statistical Package for the Social Sciences version 25.0 (SPSS Ver.25), dengan $\mathrm{p}<0,05$ dianggap signifikan. Penelitian ini telah disetujui oleh Komisi Etik Fakultas Kedokteran dan Kesehatan Universitas Muhammadiyah Jakarta dengan Nomor 094/PE/KE/FKK$\mathrm{UMJ} / \mathrm{X} / 2019$.

\section{HASIL}

Dari 153 sampel rekam medis, hasil terbanyak yaitu pada usia reproduksi sebanyak 131 kasus $(85,6 \%)$ dan pada usia tidak reproduksi sebanyak 22 kasus $(14,4 \%)$ (Tabel 1).

Sedangkan distribusi frekuensi variabel diagnosis pada sampel didapatkan leiomioma uteri 77 kasus (50,3\%), leiomioma uteri dan adenomiosis uteri 39 kasus $(25,5 \%)$ serta untuk adenomiosis uteri 37 kasus $(24,2 \%)$ (Tabel 2).

Tabel 1. Distribusi Frekuensi Variabel Usia Reproduksi

\begin{tabular}{lcc}
\hline \multicolumn{1}{c}{ Variabel } & $\begin{array}{c}\text { Frekuensi } \\
(\mathbf{n = 1 5 3 )}\end{array}$ & $\begin{array}{c}\text { Persentase } \\
(\boldsymbol{\%})\end{array}$ \\
\hline Usia Reproduksi & & \\
Usia Reproduksi & 131 & 85,6 \\
Usia tidak & 22 & 14,4 \\
Reproduksi & & \\
\hline
\end{tabular}

Tabel 2. Distribusi Frekuensi Variabel Diagnosis

\begin{tabular}{lcc}
\hline \multicolumn{1}{c}{ Variabel } & $\begin{array}{c}\text { Frekuensi } \\
(\mathbf{n = 1 5 3 )}\end{array}$ & $\begin{array}{c}\text { Persentase } \\
(\mathbf{\%})\end{array}$ \\
\hline Diagnosis & & \\
Leiomioma Uteri & 77 & 50,3 \\
Adenomiosis Uteri & 37 & 24,2 \\
Leimomioma & & \\
Uteri dan & 39 & 25,5 \\
Adenomiosis Uteri & & \\
\hline
\end{tabular}

Tabel 3. Hubungan antara Perempuan Usia Reproduksi dengan Leiomioma Uteri dan Adenomiosis Uteri

\begin{tabular}{|c|c|c|c|c|}
\hline \multirow[b]{2}{*}{ Usia } & \multicolumn{3}{|c|}{ Diagnosis Pasien } & \multirow[b]{2}{*}{$\begin{array}{c}P- \\
\text { Value }\end{array}$} \\
\hline & $\begin{array}{l}\text { Leiomioma Uteri } \\
\qquad(\mathrm{n}=77)\end{array}$ & $\begin{array}{l}\text { Adenomiosis Uteri } \\
\qquad(\mathrm{n}=37)\end{array}$ & $\begin{array}{l}\text { Leiomioma dan } \\
\text { Adenomiosis Uteri } \\
(\mathrm{n}=39)\end{array}$ & \\
\hline $\begin{array}{l}\text { Tidak Reproduksi } \\
(\leq 14 / \geq 50 \text { Tahun), } \mathrm{n} \\
(\%)\end{array}$ & $1(0,7)$ & $10(6,5)$ & $11(7,2)$ & \\
\hline $\begin{array}{l}\text { Reproduksi } \\
\text { (15 - } 49 \text { Tahun), } \\
\text { n (\%) }\end{array}$ & $76(49,7)$ & $27(17,6)$ & $28(16,3)$ & \\
\hline
\end{tabular}


Dari 153 sampel rekam medis, didapatkan diagnosis leiomioma uteri sebanyak 77 kasus $(50,4 \%)$, yaitu pada usia reproduksi sebanyak 76 kasus $(49,7 \%)$ dan pada usia tidak reproduksi sebanyak 1 kasus $(0,7 \%)$. Adapun untuk diagnosis adenomiosis uteri sebanyak 37 kasus $(24,1 \%)$, yaitu pada usia reproduksi sebanyak 27 kasus $(17,6 \%)$ dan pada usia tidak reproduksi sebanyak 10 kasus $(6,5 \%)$. Selanjutnya untuk diagnosis leiomioma uteri dan adenomiosis uteri sebanyak 39 kasus (25,5\%), pada usia reproduksi sebanyak 28 kasus $(18,3 \%)$ dan pada usia tidak reproduksi sebanyak 11 kasus $(7,2 \%)$ (Tabel 2).

Hasil uji statistik Chi-square pada Tabel 2 didapatkan nilai $p$-value yaitu 0,000 (nilai $\mathrm{p}<0,05$ ). Oleh karena itu pada penelitian ini terdapat hubungan yang bermakna antara perempuan usia reproduksi dengan leiomioma uteri dan adenomiosis uteri.

\section{PEMBAHASAN}

Berdasarkan hasil penelitian ini rata-rata usia pasien dengan leiomioma uteri, adenomiosis uteri atau keduanya adalah 42 tahun, dengan hasil usia reproduksi sebanyak 131 kasus $(85,6 \%)$ dan usia tidak reproduksi sebanyak 22 kasus (14,4\%). Usia adalah faktor risiko signifikan untuk adenomiosis uteri. Secara khusus, hampir 90 persen kasus terjadi pada wanita multipara, dan hampir 80 persen terjadi pada wanita berusia 40-an dan 50-an. Hasil ini sesuai dengan literatur yang menyebutkan bahwa leiomioma uteri dan adenomiosis uteri mengenai wanita usia reproduksi atau pada akhir tahun reproduksi $(11,12)$. Hasil tersebut juga sesuai dengan penelitian lain yang menyebutkan bahwa leiomioma uteri dan adenomiosis uteri biasanya terjadi pada usia perimenopaus (3,8,9,13-16).

Pada penelitian ini juga didapatkan leiomioma uteri 77 kasus (50,3\%), leiomioma uteri dan adenomiosis uteri 39 kasus $(25,5 \%)$ serta untuk adenomiosis uteri 37 kasus $(24,2 \%)$. Hal ini sejalan dengan literatur dan penelitian lain yang menyebutkan bahwa leiomioma uteri dan adenomiosis uteri sering muncul bersama di uterus yang sama. Prevalensi leiomioma uteri bersamaan dengan adenomiosis uteri telah dilaporkan dalam literatur berkisar antara $15-57 \%$, menurut evaluasi spesimen uterus wanita dengan leiomioma uteri $(8,10)$.

Usia rata-rata wanita dengan adenomiosis uteri dan leiomioma uteri pada histerektomi adalah 45 tahun dan berbeda dengan sebagian besar penelitian pada adenomiosis uteri saja yang melaporkan usia rata-rata adalah 40-50 tahun $(3,4,13,14)$. Penelitian yang dilakukan Meice Fitrina di Rumah Sakit Dr. Hasan Sadikin Bandung didapatkan bahwa kasus adenomiosis uteri banyak terdapat pada usia reproduksi yaitu pada usia > 35 tahun sebanyak 82 penderita $(70,7 \%)$ dengan usia rerata 39 tahun (19).

Usia perempuan dengan leiomioma uteri pada penelitian Parker et al yang meneliti wanita usia 35 sampai 49 berdasarkan analisa dari penuturan pasien, rekam medik, dan pemeriksaan sonografi ditemukan bahwa pada usia 35 tahun insiden terjadinya leiomioma uteri adalah $60 \%$ (15). Dan dalam penelitian yang dilakukan Salim di RSUD Prof. dr. Margono Soekarjo Banyumas juga menemukan bahwa penderita leiomioma uteri terbanyak ditemukan pada usia antara 40-50 tahun sebesar 63,33 \% (20).

Pada literatur lain juga disebutkan bahwa leiomioma uteri ditemukan pada 
masa reproduksi dan adenomiosis uteri ditemukan pada akhir masa reproduksi. Khususnya leiomioma uteri adalah tumor yang peka terhadap estrogen dan progesteron. Akibatnya leiomioma uteri jarang terjadi pada sebelum menarke dan berkembang selama tahun-tahun reproduksi. Setelah menopause, leiomioma uteri umumnya menyusut dan perkembangan tumor baru jarang terjadi karena pengurangan konsentrasi estrogen dalam tubuh $(2,11)$.

Secara umum hasil penelitian ini sesuai dengan literatur yang menyebutkan bahwa leiomioma uteri dan adenomiosis uteri mengenai wanita usia reproduksi atau pada akhir tahun reproduksi ${ }^{17-18}$. Serta hasil tersebut juga sesuai dengan penelitian lain yang menyebutkan bahwa leiomioma uteri dan adenomiosis uteri biasanya terjadi pada usia perimenopaus $(3,8,9,13-16)$.

\section{KESIMPULAN}

Hasil analisis hubungan antara perempuan usia reproduksi dengan kejadian leiomioma dan adenomiosis uteri menggunakan uji statistik Chi-square diatas didapatkan nilai $p=0.000(p<0,05)$. Maka penelitian ini dapat menyimpulkan bahwa terdapat hubungan antara perempuan usia reproduksi dengan kejadian leiomioma dan adenomiosis uteri di Rumah Sakit Umum Daerah Cengkareng Jakarta Barat tahun 2017-2019.

\section{UCAPAN TERIMAKASIH}

Peneliti mengucapkan banyak terima kasih pada Direktur RSUD Cengkareng Jakarta Barat yang telah memberikan ijin penelitian.

\section{KONFLIK KEPENTINGAN}

Penulis menyatakan tidak memiliki konflik kepentingan, dan tidak ada afiliasi atau koneksi dengan atau dengan entitas atau organisasi apa pun, yang dapat menimbulkan pertanyaan bias dalam diskusi dan kesimpulan naskah.

\section{REFERENSI}

1. BKKBN. Kamus Istilah Kependudukan dan Keluarga Berencana. 2011. 137 p.

2. Barbara L H. Williams Gynecology. 2nd ed. New York: Mc Graw Hil; 2012.

3. Pandey H, Pant H, Pant P, Rizvi G, Chufal S. Histopathological correlation of adenomyosis and leiomyoma in hysterectomy specimens as the cause of abnormal uterine bleeding in women in different age groups in the Kumaon region: A retroprospective study. J Midlife Health. 2013;4(1):27.

4. Vannuccini S, Petraglia F. Recent advances in understanding and managing adenomyosis [version 1; peer review: 2 approved]. F1000Research. 2019;8:1-10.

5. Prawowiroharjo S. Ilmu Kandungan. 3rd ed. Jakarta: PT. Bina Pustaka Sarwono; 2011.

6. Baziad A. Endokrinologi Ginekologi. Media Aesc. Jakarta; 2003. 151-157 p.

7. Weiss G, Maseelall P, Schott LL, Brockwell SE, Schocken M, Johnston JM. Adenomyosis a variant, not a disease? Evidence from hysterectomized menopausal women in the Study of Women's Health Across the Nation (SWAN). Fertil Steril. Elsevier Ltd; 2009;91(1):201-6.

8. Taran FA, Weaver AL, Coddington CC, Stewart EA. Understanding adenomyosis: A case control study. 
Fertil Steril. Elsevier Ltd; 2010;94(4):1223-8.

9. Taran FA, Weaver AL, Coddington CC, Stewart EA. Characteristics indicating adenomyosis coexisting with leiomyomas: A case-control study. Hum Reprod. 2010;25(5):1177-82.

10. Ates S, Ozcan P, Aydin S, Karaca N. Differences in clinical characteristics for the determination of adenomyosis coexisting with leiomyomas. J Obstet Gynaecol Res. 2016;42(3):307-12.

11. Katz VL. Comprehensive Gynecology. 5th ed. Mosby: Elsevier; 2007.

12. Abbas AK. Buku Ajar Patologi Robbins. 9th ed. Singapore: Elsevier; 2013.

13. Shaikh H, Khan KS. Adenomyosis in Pakistani women: Four year experience at the Aga Khan University Medical Centre, Karachi. J Clin Pathol. 1990;43(10):817-9.

14. Brucker SY, Huebner M, Wallwiener M, Stewart EA, Ebersoll $\mathrm{S}$, Schoenfisch B, et al. Clinical characteristics indicating adenomyosis coexisting with leiomyomas: A retrospective, questionnaire-based study. Fertil Steril. 2014;101(1):237-42.

15. Parker WH. Etiology, symptomatology, and diagnosis of uterine myomas. Fertil Steril. 2007;87(4):725-36.

16. McWilliams MM, Chennathukuzhi VM. Recent Advances in Uterine Fibroid Etiology. Semin Reprod Med. 2017;35(2):181-9.

17. Abbott JA. Adenomyosis and Abnormal Uterine Bleeding (AUBA) -Pathogenesis, diagnosis, and management. Best Pract Res Clin Obstet Gynaecol. Elsevier Ltd; 2017;40:68-81.

18. Jean-Baptiste $\mathrm{H}$, Tetrokalashvili $\mathrm{M}$, Williams T, Fogel J, Hsu CD. Characteristics associated with postoperative diagnosis of adenomyosis or combined adenomyosis with fibroids. Int $\mathbf{J}$ Gynecol Obstet. International Federation of Gynecology and Obstetrics; 2013;122(2):112-4.

19. Fitrina M, Bayuaji H, Madjid TH, Armawan E. Karakteristik Pasien Adenomiosis dengan Gambaran Ultrasonografi di Rumah Sakit Dr . Hasan Sadikin Bandung Periode 2015 - 2016 with Ultrasonographic at $\mathrm{Dr}$. Hasan Sadikin Bandung General Hospital. 2016;35-9.

20. IA S. Karakteristik Leiomyoma di RSUD Prof. dr. Margono Soekarjo Banyumas. Medisains. 2015;13(3). 